\title{
Modeling the costs and benefits of capnography monitoring during procedural sedation for gastro- intestinal endoscopy
}

Authors

Institutions
Rhodri Saunders ${ }^{1}$, Mary Erslon ${ }^{2}$, John Vargo ${ }^{3}$

${ }^{1}$ Ossian Health Economics and Communications, Basel, Switzerland (current affiliation: Coreva Scientific, Freiburg, Germany) ${ }^{2}$ Covidien, Boulder, Colorado, United States (current affiliation: Medtronic, Boulder, Colorado, United States)

${ }^{3}$ Cleveland Clinic, Cleveland, Ohio, United States submitted

30. September 2015

accepted after revision

4. January 2016

\section{Bibliography}

DOI http://dx.doi.org/

10.1055/s-0042-100719

Endoscopy International Open 2016; 04: E340-E351

(c) Georg Thieme Verlag KG Stuttgart · New York

E-ISSN 2196-9736

\section{Corresponding author}

\section{Rhodri Saunders}

Coreva Scientific

Freiburg

Germany

Phone: +49-76-176-999-422

Rhodri@coreva-scientific.com
Background and study aims: The addition of capnography to procedural sedation/analgesia (PSA) guidelines has been controversial due to limited evidence of clinical utility in moderate PSA and cost concerns.

Patients and methods: A comprehensive model of PSA during gastrointestinal endoscopy was developed to capture adverse events (AEs), guideline interventions, outcomes, and costs. Randomized, controlled trials and large-scale studies were used to inform the model. The model compared outcomes using pulse oximetry alone with pulse oximetry plus capnography. Pulse oximetry was assumed at no cost, whereas capnography cost USD 4,000 per monitor. AE costs were obtained from literature review and Premier database analysis. The model population $(n=8,000)$ had mean characteristics of age 55.5 years, body mass index $26.2 \mathrm{~kg} / \mathrm{m}^{2}$, and $45.3 \%$ male.

Associated presentations: Aspects of this work have been accepted for poster publication at Anesthesiology 2015 (San Diego, United States) and E-ISPOR 2015 (Milan, Italy)

\section{Introduction}

$\nabla$

Diagnostic and therapeutic procedures undertaken as part of standard healthcare can be unpleasant, distressing and painful for patients $[1,2]$. Provision of sedation and analgesia to limit patient distress is common and has been shown to increase the success rate of procedures such as colonoscopy [3]. The aim of procedural sedation and analgesia (PSA) is to reduce patients' consciousness and pain recognition while retaining their continuous, independent ventilation, and protective reflexes [4]. The role of PSA has been growing as sedation outside the operating room and/or without anesthesiologist assistance becomes more common [5,6]. A comparison of gastroente-
Results: The addition of capnography resulted in a $27.2 \%$ and $18.0 \%$ reduction in the proportion of patients experiencing an $\mathrm{AE}$ during deep and moderate PSA, respectively. Sensitivity analyses demonstrated significant reductions in apnea and desaturation with capnography. The median (95\% credible interval) number needed to treat to avoid any adverse event was $8(2 ; 72)$ for deep and $6(-59 ; 92)$ for moderate. Reduced AEs resulted in cost savings that accounted for the additional upfront purchase cost. Capnography was estimated to reduce the cost per procedure by USD 85 (deep) or USD 35 (moderate).

Conclusions: Capnography is estimated to be cost-effective if not cost saving during PSA for gastrointestinal endoscopy. Savings were driven by improved patient safety, suggesting that capnography may have an important role in the safe provision of PSA.

rology procedures in the United States between 2003 and 2009 found that although the number of procedures performed in Medicare patients remained roughly constant, the percentage of procedures using anesthesia increased from $13.5 \%$ to $30.2 \%$ [6].

The use of PSA is not without both risks and costs. Reports suggest that PSA accounts for approximately $75 \%$ of the time and $40 \%$ of the cost associated with endoscopy [7]. Monitoring of PSA is mandatory because there is a risk of patients progressing into deeper, unintended levels of sedation; guidelines recommend that one healthcare professional be specifically tasked with monitoring $[5,8]$. Still, adverse events (AEs) such as apnea, desaturation, and hypotension occur. Observational and retrospective studies indicated low rates of AEs, with $1.6 \%$ to $2.4 \%$ of patients experiencing oxygen desaturation $<90 \%$ during PSA [911]. Randomized, controlled trials, however, generally report higher values (13\% to $69 \%$ ) [12-14]. 


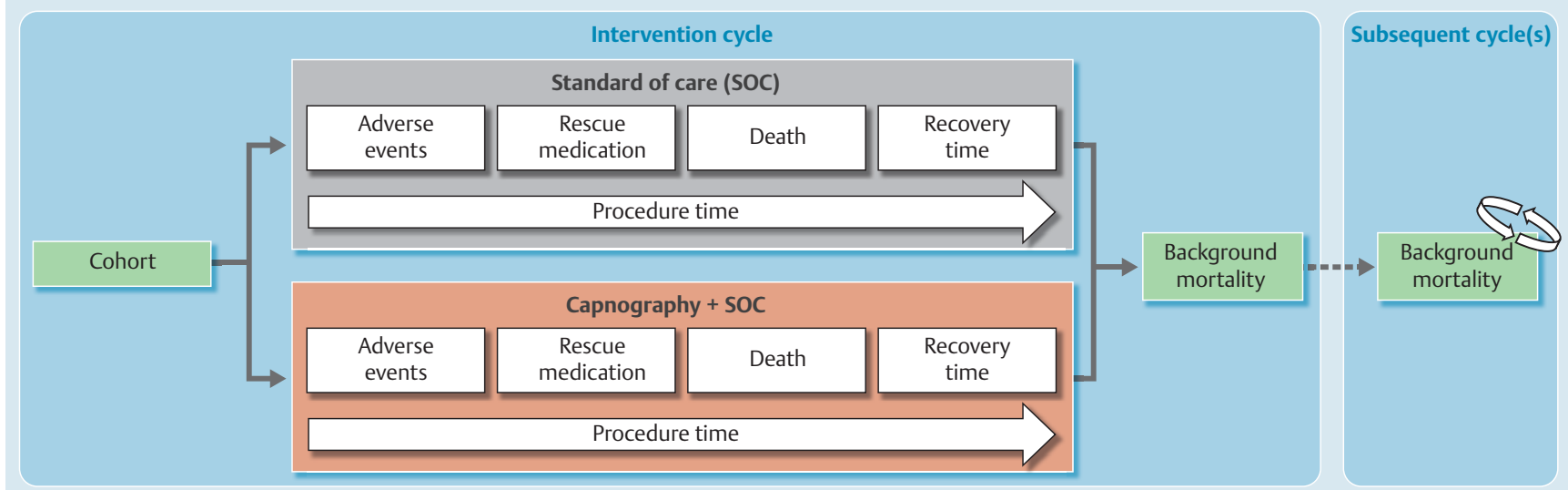

Fig. 1 Overview of the model structure. The model runs on a cohort basis. Based on study data, a proportion of patients will experience a model outcome. The likelihood of events is provided for the standard-of-care arm, with an odds ratio used to estimate the likelihood of events in the capnography arm. Adverse events, rescue medication, and death are all assumed to take place during the procedure and can impact on the procedure time, while presence of events can influence recovery time.

The occurrence of AEs further adds to the care and cost burden placed on hospitals [15-17].

Standard-of-care monitoring for PSA is pulse oximetry, visual assessment and blood pressure measurement, with adjunct monitoring with capnography a Level B recommendation in the emergency room setting and when PSA targets deep sedation for endoscopy [8]. Capnography monitoring evaluates carbon dioxide in exhaled air and provides a measure of patient ventilation. Randomized, controlled trials have demonstrated that capnography in addition to pulse oximetry can reduce the occurrence of specific AEs in both pediatric patients targeting moderate sedation and adults receiving propofol-mediated deep sedation [12$14,18]$. To date, there are no adult studies addressing the utility of capnography with PSA targeting moderate sedation. Furthermore, two studies published in 2015 indicate that capnography leads to earlier identification of compromise and a reduced need for intervention $[19,20]$. Both of these series, however, did not involve gastrointestinal endoscopy. There is no meta-analysis that quantifies the impact of capnography monitoring on AEs to provide the highest level of evidence to inform clinical decision making. As such, moves to include capnography monitoring in the standard of care for PSA targeting moderate sedation have been controversial and met with resistance [21]. Key objections were the level of evidence supporting capnography in PSA and in particular, in adults receiving moderate sedation, the lack of standardized outcome definitions for apnea or disordered respiration and the added monetary burden of a costly technology [21].

Capnography is the standard of care for monitoring sedation in other hospital settings, including PSA targeting deep sedation and monitoring patients receiving mechanical ventilation where clinical trial data indicate its benefit [14, 22 - 24]. The highest level of synthesized evidence supporting the patient benefits of capnography is, however, lacking and no studies to date have evaluated the cost of capnography monitoring during PSA. This analysis evaluates whether the cost of adding capnography represents a reasonable barrier to its addition to the standard of care during PSA. Due to data availability and the fact that AE rates vary by procedure, the analysis focuses on gastrointestinal endoscopic procedures.

\section{Patients and methods \\ $\nabla$}

A comprehensive model of PSA was developed in Microsoft Ex$\mathrm{cel}^{\circledR}$. It was considered comprehensive because it considers all major patient, staff, location, and monitoring characteristics that influence the adverse event rate and takes into account the costs and/or time associated with product acquisition and maintenance, staff training, and $\mathrm{AE}$ resolution. The objective of this decision analytic model was to provide a robust estimate of the cost per additional/avoided AE for the addition of capnography to pulse oximetry during PSA. Additional outcomes estimated were the cost per procedure and the number needed to treat (NNT) for each AE considered. The model complied with good practice guidelines as published by the International Society of Pharmacoeconomics and Outcomes Research (ISPOR) [25]. Where published data were unavailable to inform the model, expert opinion was sought or primary data collection was undertaken. The structured literature search used to identify relevant literature in the PubMed database is presented in the supplementary material. Equivalent searches were undertaken in EMBASE and the Cochrane Library. The quality of randomized, controlled trials returned and considered for use in the model was assessed using a modified Jadad score (supplementary material).

The model considers a cohort of patients that undergo PSA. In the model, PSA is performed with pulse oximetry monitoring or pulse oximetry and capnography monitoring ( $\bullet$ Fig. 1 ) and both arms include visual and blood pressure assessment. The model has a 1-year cycle length, with subsequent cycles only considering background mortality taken from US life tables. In each model arm, the risk of AEs including apnea, aspiration, bradycardia, desaturation, hypotension, and respiratory failure is assessed via a decision tree $(\bullet$ Fig. 2 ) with transition probabilities derived from randomized controlled trials and large observational studies ( Table 1 and supplementary material). Because a single patient can have multiple AEs, each AE considered is its own decision tree. Interventions to treat AEs $(-$ Table 2$)$ were taken from guidelines. Outcomes dependent on experiencing an $\mathrm{AE}$ were also estimated and they were mortality, anesthesiologist intervention, unplanned admission, and procedure termination. Serious AEs were associated with a risk of legal action.

Patients experiencing an $\mathrm{AE}$ were exposed to the risk of each $\mathrm{AE}$ occurring ( $\bullet$ Fig. 2). For each AE that occurs, the proportion of pa- 
Table 1 Adverse event rates and rates of associated events during procedural sedation in adults.

\begin{tabular}{|c|c|c|c|}
\hline Event & Rate & Study detail & Reference \\
\hline \multicolumn{4}{|l|}{ Adverse event } \\
\hline Airway obstruction & 0.05 & No data & Assumption \\
\hline Apnea & 0.13580 & 33 events in 243 patients during a prospective trial & {$[27]$} \\
\hline Aspiration & 0.00031 & $\begin{array}{l}\text { Review indicating that aspiration is rare, reporting one trial in adults with } 1 \text { event } \\
\text { in } 3,216 \text { procedures (general anesthesia) }\end{array}$ & {$[40]$} \\
\hline Bradycardia & 0.08300 & Incidence rate of $8.3 \%$ in an randomized, controlled trial & {$[12]$} \\
\hline Desaturation $(<90 \%)$ & 0.19800 & Incidence rate of $19.8 \%$ in an randomized, controlled trial & [12] \\
\hline Desaturation $(<85 \%)$ & 0.07800 & Incidence rate of $7.8 \%$ in an randomized, controlled trial & {$[12]$} \\
\hline Hypotension & 0.08230 & 20 events in 243 patients during a prospective trial & {$[27]$} \\
\hline Respiratory failure & 0.00295 & $\begin{array}{l}\text { Due to a range of definitions and rates, the mean rate was taken from a Scandinavian study } \\
(0.4 \%) \text { and a US study }(0.19 \%)=0.00295\end{array}$ & {$[41,42]$} \\
\hline \multicolumn{4}{|l|}{ Adverse outcomes } \\
\hline $\begin{array}{l}\text { Anesthesiologist } \\
\text { intervention }\end{array}$ & 0.00316 & $\begin{array}{l}\text { Of } 78 \text { hypoxemia events and } 554 \text { hypotension events an anesthesiologist was called } 10 \text { times, in } \\
\text { only } 2 \text { cases was intervention required. Rate of } 2 /(78+554)\end{array}$ & {$[43]$} \\
\hline Mortality & 0.000006 & 1 death in every 161,515 procedures, from a study of $>600,000$ cases & {$[44]$} \\
\hline Premature termination & 0.00823 & 2 events in 243 patients during a prospective trial & [27] \\
\hline Unplanned admission & 0.00293 & 28 patients out of 9547 procedures (over 6 years) needed extra care in the intensive care unit & [41] \\
\hline \multicolumn{4}{|l|}{ Legal action } \\
\hline A legal claim is made & 0.000567 & $\begin{array}{l}\text { There were } 38 \text { claims from an analysis of } 67,000 \text { procedures undertaken between } 2004 \text { and } \\
2009\end{array}$ & [33] \\
\hline $\begin{array}{l}\text { Results in a settlement } \\
\text { or damages }\end{array}$ & 0.000318 & $56 \%$ of claims (from remote locations) were paid, rate is $56 \%$ of that for a legal claim made & {$[15]$} \\
\hline
\end{tabular}

tients that experience this $\mathrm{AE}$ was exposed to the probability of each intervention that is used to treat the AE. Finally, each $\mathrm{AE}$ was associated with a risk of an adverse outcome (e.g. mortality) and each intervention and outcome was associated with both a time and monetary cost ( Table2). A 2013 study reported that patients who experienced an AE during PSA had a longer recovery time, specifically 20 minutes with an AE compared with 12 minutes without an $\mathrm{AE}$ [26]. In the model, patients who experience an $\mathrm{AE}$ are retained in the recovery room for an extra $8( \pm 4)$ minutes.

\section{Model cohort and patient characteristics}

The mean cohort characteristics of the model population were derived from two recent studies, one randomized, controlled trial and one prospective cohort study, undertaken in the US setting $[14,27]$. Combining data from these studies (supplementary material) provided a patient cohort with mean (standard deviation, SD) characteristics of: age 55.5 (14.8) years, $45.3 \%$ male, body mass index (BMI) $26.2(5.9) \mathrm{kg} / \mathrm{m}^{2}$, and an American Society of Anesthesiologists (ASA) classification of I, II, III, and IV of $4.9 \%$, $50.6 \%, 44.5 \%$, and $0 \%$, respectively. For gender and ASA class, the

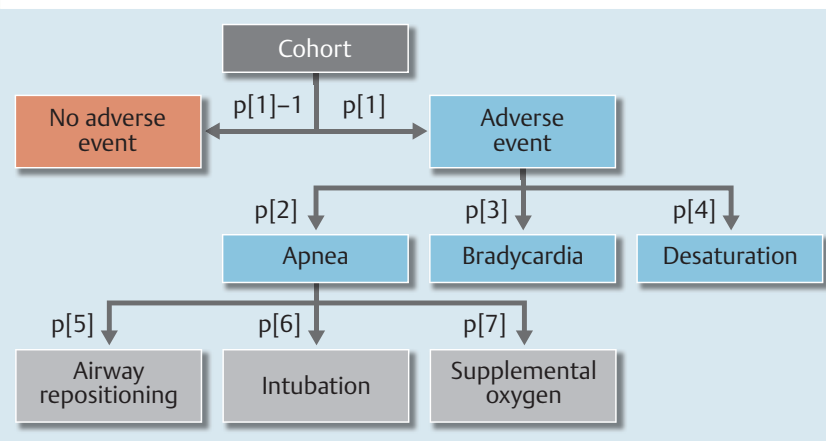

Fig. 2 Assessing outcomes in the cohort using a decision tree. $\mathrm{p}[\mathrm{N}]$ is the probability of the outcome, where $\mathrm{N}$ is the number of the transition in question. In this example, not all possible transitions and trees are shown. standard deviation was assumed to be $10 \%$ during sensitivity analyses.

Following reports from clinical studies, patient cohort characteristics were used to modulate the risk of experiencing an AE. The study by Wani et al. found that sedation-related AEs were significantly associated with patient age and BMI [28]. It has also been reported that ASA class is associated with the likelihood of experiencing an AE [29]. The ORs reported are modelled as independent variables and combined to provide a cohort level OR for AEs (supplementary material). In general, a cohort of older patients with higher BMI and a greater proportion of patients in ASA classes III and IV would be most likely to experience AEs. The odds of an AE were also modulated by the healthcare professional performing the monitoring and the procedure location. These data are assumed to be dependent, with the healthcare professional performing the monitoring being the dominant factor (supplementary material).

\section{Capnography}

Impact on adverse events

Clinical studies have indicated that capnography can influence the rate at which AEs are experienced ( $\square$ Table 3 ). These data are taken exclusively from studies utilizing PSA targeting deep sedation. Due to heterogeneity of data in the literature, both significant and non-significant differences between study arms were modeled, with uncertainty explored through sensitivity analyses; thus, a finding of "no significant difference" was not taken to mean no difference between trial arms. If no data were available for an $\mathrm{AE}$, then no difference between pulse oximetry and pulse oximetry plus capnography was modeled (an odds ratio [OR] of 1). In each case where the data for the ORs were presented in the literature, the standard error and 95\% confidence intervals were calculated (supplementary material). The clinical trials of capnography generally report data for deep rather than moderate PSA. 
Table 2 Interventions in the model and their associated cost and frequency of use.

\begin{tabular}{|c|c|c|c|c|}
\hline Intervention & Related adverse events (Reference) & Probability (Reference) & $\begin{array}{l}\text { Time, min } \\
(\mathrm{SD})^{1}\end{array}$ & $\begin{array}{l}\text { Cost, USD } \\
\text { (SD) }\end{array}$ \\
\hline Supplemental oxygen & $\begin{array}{l}\text { Desaturation, bradycardia, [45] assumed also aspiration and } \\
\text { respiratory compromise }\end{array}$ & $0.57800[46]$ & $0.5(0.3)$ & $10(2)^{2}$ \\
\hline Airway repositioning & $\begin{array}{l}\text { Desaturation, apnea (obstructive), airway obstruction, bra- } \\
\text { dycardia, [45] assumed also aspiration }\end{array}$ & $0.35316[46]$ & $0.2(0.1)$ & $0(0)^{2}$ \\
\hline Intubation & $\begin{array}{l}\text { Desaturation, apnea (central), airway obstruction, brady- } \\
\text { cardia [45], assumed also aspiration and respiratory com- } \\
\text { promise }\end{array}$ & $0.00980[46]$ & $5.0(2.5)$ & $126(25)^{3}$ \\
\hline CPAP & Assumed aspiration and respiratory compromise & $0.06916[46]$ & $3.0(1.5)$ & $604(121)^{3}$ \\
\hline Positive pressure ventilation & Desaturation, apnea (obstructive), airway obstruction [45] & $0.32416[46]$ & $3.0(1.5)$ & $604(121)^{4}$ \\
\hline Nasal airway & Desaturation, apnea (obstructive), airway obstruction [45] & $0.06112[9]$ & $5.0(2.5)$ & $948(190)^{3}$ \\
\hline Oral airway & Desaturation, apnea (obstructive), airway obstruction [45] & $0.00916[46]$ & $5.0(2.5)$ & $948(190)^{4}$ \\
\hline Stimulation & Desaturation, apnea (central), bradycardia [45] & $0.10816[46]$ & $0.2(0.1)$ & $0(0)^{2}$ \\
\hline Reversal agents & Apnea (central), [45] assumed also respiratory compromise & $0.00870[27]$ & $5.0(2.5)$ & $40(8)^{2}$ \\
\hline Bag mask ventilation & $\begin{array}{l}\text { Apnea (central), airway obstruction, bradycardia, [45] } \\
\text { assumed also desaturation }\end{array}$ & $0.00821[9]$ & $5.0(2.5)$ & $12(3)^{3}$ \\
\hline Suctioning & $\begin{array}{l}\text { Desaturation, apnea (obstructive), airway obstruction, } \\
\text { bradycardia, [45] assumed also desaturation }\end{array}$ & $0.03920[46]$ & $2.0(1.0)$ & $100(20)^{2}$ \\
\hline Additional sedation & Airway obstruction [45] & $0.33800[29]$ & $1.0(0.5)$ & $541(108)^{3}$ \\
\hline Neuromuscular blockade & Airway obstruction [45] & 0.00411 (assumption) & $1.0(0.5)$ & $100(20)^{2}$ \\
\hline Chest compressions & $\begin{array}{l}\text { Bradycardia, hypotension, [45] assumed also respiratory } \\
\text { compromise }\end{array}$ & $0.01200[29]$ & $5.0(2.5)$ & $0(0)^{2}$ \\
\hline IV fluids & Hypotension, [45] assumed also respiratory compromise & $0.01500[29]$ & $5.0(2.5)$ & $19(4)^{3}$ \\
\hline Code blue & Assumed apnea and respiratory compromise & 0.00411 (assumption) & $15.0(7.5)$ & $1000(200)^{2}$ \\
\hline
\end{tabular}

Abbreviations: CPAP, continuous positive airway pressure; IV, intravenous; SD, standard deviation; USD, United States dollar

${ }^{1}$ All values are assumptions for mean values based on clinical practice experience of JV and colleagues

${ }^{2}$ Values are assumptions as no cost data were available

${ }^{3}$ Value derived from analysis of the PREMIER database, 2012-2013

${ }^{4}$ Assumed equal to CPAP and nasal airway, respectively

Table 3 Odds ratios for capnography event rates.

\begin{tabular}{|c|c|c|c|c|}
\hline Adverse event & Odds ratio $(95 \% \mathrm{Cl})$ & SE & Study detail & Reference \\
\hline Apnea & $0.417(0.25-0.7)$ & 0.26 & $\begin{array}{l}\text { Occurred in } 62.6 \% \text { of patients receiving standard of care and } 41.1 \% \text { of patients } \\
\text { receiving standard of care plus capnography }\end{array}$ & [14] \\
\hline Bradycardia & $1.146(0.69-1.9)$ & 0.26 & $\begin{array}{l}\text { Occurred in } 8.3 \% \text { of patients receiving standard of care and } 9.4 \% \text { of patients } \\
\text { receiving standard of care plus capnography }\end{array}$ & [12] \\
\hline Desaturation ( $<90 \%)$ & $0.579(0.39-0.86)$ & 0.20 & $\begin{array}{l}\text { Occurred in } 19.8 \% \text { of patients receiving standard of care and } 12.5 \% \text { of patients } \\
\text { receiving standard of care plus capnography }\end{array}$ & [12] \\
\hline Desaturation $(<85 \%)$ & $0.454(0.23-0.87)$ & 0.33 & $\begin{array}{l}\text { Occurred in } 7.8 \% \text { of patients receiving standard of care and } 3.7 \% \text { of patients } \\
\text { receiving standard of care plus capnography }\end{array}$ & [12] \\
\hline Hypotension & $1.052(0.51-2.14)$ & 0.37 & $\begin{array}{l}\text { Occurred in } 4.0 \% \text { of patients receiving standard of care and } 4.2 \% \text { of patients } \\
\text { receiving standard of care plus capnography }\end{array}$ & [12] \\
\hline Respiratory failure & 0.215 (NA) & 0.11 & $\begin{array}{l}\text { Calculated from the OR of } 17.6 \text { for increased detection of respiratory depression, } \\
\text { and assumes that after identification of an event } 10 \% \text { can be avoided }\end{array}$ & [30] \\
\hline
\end{tabular}

Abbreviations: $\mathrm{Cl}$, confidence interval; NA, not applicable; SE, standard error

False positives

The model accounted for interventions and time associated with false-positive events. As these events were false positives, potential interventions were restricted to supplemental oxygen and airway repositioning. In the clinical trial by Qadeer et al., 35 of the 263 patients assessed with capnography erroneously presented with apnea [14]. The probability of pseudo apnea was thus 0.1331. In the meta-analysis by Waugh et al., 71 false-positive and 157 true-negative events were reported, giving a falsepositive probability of 0.3114 with capnography monitoring [30]. This study analyzed multiple definitions of respiratory compromise and the probability $(0.3114)$ is thus assumed to include the probability of pseudo apnea $(0.1331)$ and was adjusted to
0.1783 (0.3114-0.1331). Given the multiple AEs definitions included, the probability was assigned to airway obstruction.

\section{Costs}

Model costs included the purchase of hardware and disposables, interventions, healthcare professional time (in the procedure and for monitor training and maintenance), and outcomes. All costs are presented in 2014 USD. Where costs were provided in earlier years, these values were inflated to 2014 USD using inflation rates provided by US Bureau of Labor Statistics [31]. Table 2 lists the costs of interventions and also includes the time required for each intervention. The costs for healthcare professional time (per hour) were obtained from analysis of the Premier Data- 
Table 4 Events avoided with capnography and the number needed to treat.

\begin{tabular}{|llll}
\hline Parameter & $\begin{array}{l}\text { Base case events avoided } \\
\text { with capnography, } \mathbf{n}^{\mathbf{1}}\end{array}$ & $\begin{array}{l}\text { Base case number needed } \\
\text { to treat, } \mathbf{n}\end{array}$ & $\begin{array}{l}\text { Probabilistic sensitivity analyses, } \\
\text { median number needed to treat (95\% Crl) }\end{array}$ \\
\hline Adverse event & 0 & $\# \mathrm{~N} / \mathrm{A}$ & $-26(-7,573 ; 6605)$ \\
\hline Airway obstruction & 564 & 14 & $15(5 ; 91)$ \\
\hline Apnea & 0 & $\# \mathrm{~N} / \mathrm{A}$ & $-1,176(-426,551 ; 468,692)$ \\
\hline Aspiration & -83 & -96 & $-32(-691 ; 534)$ \\
\hline Bradycardia & 356 & 22 & $25(8 ; 159)$ \\
\hline Desaturation (<90\%) & 310 & 26 & $29(7 ; 202)$ \\
\hline Desaturation (<85\%) & -30 & -270 & $-14(-554 ; 553)$ \\
\hline Hypotension & 17 & 458 & $451(74 ; 2,952)$ \\
\hline Respiratory failure & 1134 & 7 & $8(2 ; 57)$ \\
\hline Any adverse event & & & $1960(-5,143 ; 21,125)$ \\
\hline Adverse outcome & 5 & 1,613 & 2094526 \\
\hline Anesthesiologist intervention & $1,738,205$ & $1323(-3,344 ; 14,776)$ \\
\hline Mortality & 0 & 1,109 & $7073(-17,831 ; 79,074)$ \\
\hline Premature termination & 7 & 5,915 & $703(-1,877 ; 7,409)$ \\
\hline Unplanned admission & 1 & 591 & \\
\hline Any adverse outcome & 14 & & \\
\hline
\end{tabular}

Abbreviation: $\mathrm{Crl}$, credible interval.

${ }^{1}$ Events avoided in a cohort of 8,000 patients; value rounded to the nearest integer. Negative value indicate additional events with capnography.

base for years 2012 - 2013, with the exception of "other" which was taken from Couloures et al. 2011 [32]. The Premier database (Premier Inc., Charlotte, North Carolina) includes data on approximately $20 \%$ of all US hospitalizations annually. It includes all International Classification of Diseases-9th Revision-Clinical Modification diagnosis and procedure codes recorded by the hospital, as well as a limited set of Current Procedural Terminology4. The discharge-level data also include hospital resource utilization and charges/costs (for all payers).

As no data were available, the mean (standard deviation, SD) cost of death, premature termination, and hospital admission was assumed to be USD 5,000 (1,000). A mean (SD) cost of a legal claim was assumed to be USD 25,000 (5,000), and damages (if paid) were taken from the midpoint of the interquartile range presented by Ferguson et al., [33] USD 225,000 (45,000).

Purchase of a pulse oximetry monitor was assumed to be at no cost, whereas capnography cost USD 4,000 per monitor and USD 16 per procedure for disposables (double that for pulse oximetry at USD 8.10). Both types of monitoring were associated with training and maintenance requirements. Training for capnography was assumed to be 2 hours per month per trained staff member, compared with 0.5 hours for pulse oximetry. Maintenance and calibration was assumed to require 2 hours of time per month from one technician ("other").

\section{Base case analysis}

In addition to data presented previously, the base case scenario uses the following parameters: time horizon of 1 year, a cohort of 8,000 patients, four monitors/rooms in use, 16 staff trained to use the monitoring equipment, and three staff present during the procedure.

\section{Sensitivity analyses}

The model supports one-way and probabilistic sensitivity analyses, which were programmed in Excel using Visual Basic for Applications. For each simulation in the probabilistic sensitivity analyses, every model input parameter was set at random, with the value for each parameter for each simulation sampled from a distribution. For each parameter, a distribution was defined by the mean (base case value) and a measure of its variance (standard deviation or standard error). A value between zero and one is then sampled from a uniform distribution and used to identify the parameter value for the simulation through lookup on the cumulative distribution function.

In most cases a normal distribution was used to represent each input parameter, the exceptions being ratios that were sampled from log-normal distributions. Through probabilistic sensitivity analyses the variability in model parameters and their influence on model outcomes can be explored. Results are presented for 5,000 simulations as the median and $95 \%$ credible interval $(\mathrm{CrI})$. A $95 \% \mathrm{CrI}$ is the range within which $95 \%$ of results lie, with the bottom $2.5 \%$ and the top $2.5 \%$ of results excluded. In this way it captures all "reasonable" results. It differs from a confidence interval about the mean (which indicates the range within which the mean of the true distribution could lie), as it is not a summary measure of the distribution but describes the full range of results. The $\mathrm{CrI}$ is particularly suited to modelling outcomes because it does not require normally distribution of data for it to be valid. One-way sensitivity analyses assessed the robustness of model outcomes to changes in the unit cost of items. A further analysis was undertaken to evaluate the impact of capnography during moderate PSA. In this scenario, event rates and odds ratios (supplementary material) were updated to reflect those in the studies focused on moderate sedation and the patient population was split equally between ASA class I and II [34-36].

\section{Results \\ $\nabla$}

\section{Base case}

The addition of capnography to pulse oximetry monitoring during PSA results in an overall reduction in AEs. Over the whole cohort, 1,134 AEs were avoided in the capnography arm ( $\bullet$ Table 4). Apnea was the most commonly avoided AE with capnography. There were also substantial reductions in the number of desaturation events in the cohort with capnography monitoring. 
Two AEs exhibited an increase in occurrence with capnography: 30 additional hypotension and 83 additional bradycardia events. In terms of patients experiencing AEs, the percentage of those with an AE was $34.18 \%$ with pulse oximetry monitoring and $24.89 \%$ with capnography (absolute reduction $9.29 \%$; relative reduction $27.18 \%$ ).

The NNT to avoid one AE with the addition of capnography was seven ( Table 4), while the NNT to avoid one adverse outcome, 591, was much larger. Although no single mortality event was avoided in the base case cohort, estimates indicated that capnography would result in a reduction in patient mortality, with one event avoided every 1.7 million procedures. Due to the lower incidence of AEs, the addition of capnography was associated with a mean reduction in procedure time.

Adding capnography during PSA was estimated to reduce the cost per procedure by USD 85 (USD 156 versus USD 241). Because capnography reduced the number of AEs and resulted in cost savings compared with pulse oximetry alone, the analysis indicated that capnography was dominant to standard of care. In this analysis, cost-effectiveness was influenced by the cohort size because procurement costs were distributed over the number of procedures performed. In a breakeven analysis, capnography increased the mean cost per procedure if $\leq 294$ procedures were undertaken, whereas cost savings were realized from procedure number 295 onwards.

\section{Sensitivity analyses}

Examining the robustness of cost outcomes through probabilistic sensitivity analyses, the median outcome was a cost saving of USD 75 with a $95 \%$ CrI of -10 to 302 ( $\bullet$ Fig. 3). Overall, the addition of capnography dominated standard of care in 4,483 of 5,000 simulations (89.7\%). There were 498 simulations (10.0\%) in which capnography was associated with an increase in the mean cost; in this subset of simulations, the cost per AE avoided with capnography was USD 2,165. Examining cost drivers through one-way sensitivity analyses, the majority of cost items had only a small influence on the cost differential between pulse oximetry and capnography (supplementary material). Doubling

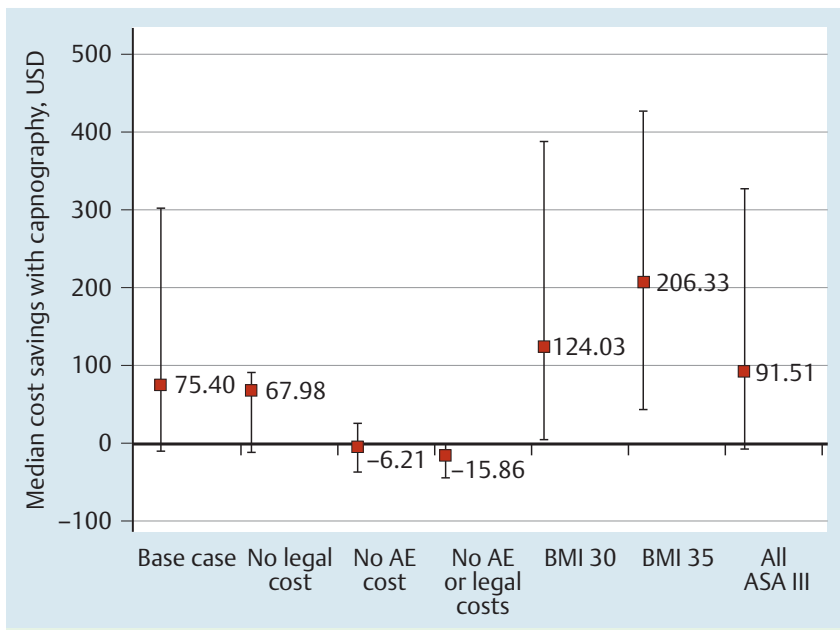

Fig. 3 Median (95\% credible interval) cost saving associated with capnography monitoring under different scenarios, $n=5,000$ simulations for each. Negative cost savings reflect a cost increase.

Abbreviations: AE, adverse event; ASA, American Society for Anesthesia; BMI, body mass index; USD, United States Dollar. the price of the capnography monitor decreased the cost saving by only $2.3 \%$.

Because time required for interventions was an assumed value, an analysis in which that value was set to zero was undertaken. The cost saving associated with capnography was reduced by less than 1 USD in this test. Overall, assumptions in the model had little impact on model outcomes. In a scenario in which AEs were associated with no costs, capnography increased the median cost per procedure by USD 6 ( $\bullet$ Fig.3). This value was USD 16 if legal costs and damages were also excluded from the model. The addition of capnography monitoring would, however, still likely be considered cost effective at USD 96 per AE avoided in this scenario. Obesity is becoming an increasing global problem and higher BMI is associated with a higher rate of AEs [28] To explore how obesity influences the model, the mean cohort BMI was increased to 30 and $35 \mathrm{~kg} / \mathrm{m}^{2}$, which resulted in significant cost savings, median USD 129 (95\% CrI, 8 to 378) and USD 206 (95\% CrI, 43 to 462), respectively.

Outside of cost differentials, probabilistic sensitivity analyses demonstrated that capnography monitoring has important implications for patient safety. The median NNT to prevent one AE with capnography monitoring was 8 (95\% CrI, 2 to 72, Table 4). Significant reductions in AEs were also identified, with desaturation $<90 \%$, desaturation $<85 \%$, and respiratory failure requiring a median NNT of 24,28 , and 432 , respectively. There was no significant increase in any AE with capnography monitoring. When event rates reflecting moderate PSA were used, capnography was associated with an $18.0 \%$ reduction in the percentage of patients experiencing an AE. The cost-saving was reduced relative to deep PSA, being USD 55 in the base case and a median of USD 36 (95\% CrI, -96 to 247) under probabilistic sensitivity analysis. The NNT to avoid any AE was not significant for moderate PSA, median 6 (95\% CrI, -59 to 92). Although the credible intervals were wide, $79.9 \%$ and $68.0 \%$ of the 5,000 simulations resulted in a reduced number of AEs and a cost saving with capnography, respectively. Significant reductions were found for severe desaturation, the median NNT being 17 (95\% CrI, 4 to 307).

\section{Discussion}

The developed model provides a comprehensive representation of PSA, accounting for patient characteristics, the monitoring environment, AEs, and the time and cost required to treat these events. Furthermore, the impact of events on outcomes is considered. Although capnography is associated with an upfront cost burden in terms of both acquisition costs and staff training time, over 1 year, these costs were completely offset. The model estimates that capnography was cost saving in the base case, and cost saving or cost-effective under a number of other scenarios. The cost per procedure with pulse oximetry estimated by the model (USD 241) is in line with previously published values. An imaging procedure with PSA was estimated to be USD 230-256 in 2000 [37]. A randomized, controlled trial found that the cost of an esophagogastroduodenoscopy with PSA was USD 512, but that included USD 260 of room and recovery room costs not captured in the current model [38]. Consistency of outcomes with these earlier studies is encouraging and supports the clinical utility of estimates derived from this analysis.

Our study found that the addition of capnography to the normal monitoring avenues of pulse oximetry, blood pressure, electrocardiography and visual assessment led to a $27.2 \%$ decrease in the number of AEs with deep PSA. This included both apnea and hypoxia. An important finding of the study was that the decrease 
in AEs was also seen in endoscopic procedures targeting moderate sedation, which has been a point of controversy due to the previous lack of data. Because the vast majority of cardiopulmonary AEs are precipitated by ventilation abnormalities or hypoxia, the number needed to treat for these outcomes ( 8 for hypoxia and 15 for apnea) appears to be an appropriate investment to avoid AEs for both moderate sedation as well as deeper levels of sedation. Furthermore, a recent study on consecutive anesthesia patients found that perioperative hypoxia was associated with increased length of time in hospital [39] From a population-based perspective, the addition of capnography may have multiple advantages and in this analysis, it led to costs savings through its ability to prevent significant AEs and the costs associated with them.

As with all health economic analyses, there are limitations to this study. Respiration can also be monitored using technology such as chest impedance and acoustic airflow; as no head-to-head trials have been performed, the comparative effectiveness of the technologies is unknown and is not included in this model. Furthermore, not all AEs are equal in terms of cost and severity. The model described accounts for cost but not severity of AEs. The reason for this being that no patient quality of life data were available to inform the model. In terms of AE severity, reductions in mortality, respiratory failure, and severe desaturation are most important from both a patient and provider standpoint.

In developing a comprehensive model of PSA, notably a number of parameters supported by the model could not be sourced from published sources. The percentage of patients experiencing an AE varies considerably between studies, likely due to differences in study design and endpoint definitions. To make comparisons between monitoring strategies, the number of patients experiencing an $\mathrm{AE}$ was required. This value in the model was restricted due to the rates of AEs used, being mathematically constrained to between $13.58 \%$ and $55.24 \%$ in adults. A further key assumption is that the mean number of AEs experienced per patient is the same for both standard-of-care monitoring and capnography monitoring. The impact of assumptions on model outcomes was tested through sensitivity analyses. The fact that results remained relatively consistent provides support to the validity of the model and the robustness of conclusions drawn from it. Still, the model is populated with data on gastroendoscopy and results presented should not be assumed to apply to all aspects of PSA.

Overall, estimates from this modeling analysis indicate that capnography can reduce the incidence of AEs and increase patient safety during PSA at no or relatively insignificant extra cost. Concerns regarding the additional cost of capnography during PSA are therefore likely to be unfounded for gastroendoscopy. Outcomes are, however, derived from a model and additional data from clinical studies that collect direct costs would be advantageous in further informing decisions in this area. Most appropriate would be the collection of costs during a randomized, controlled trial. Whether such a study is feasible given the patient numbers required to observe sufficient adverse outcomes is debatable. Only clinical trials enrolling over 500 patients have been able to identify respiratory failure and the need for assisted ventilation [12]. Early identification and reduced need for intervention identified recently for capnography highlights the potential to reduce failure to rescue [20], which could have an important impact on cost-effectiveness. Based on currently available data, this health economic analysis demonstrated that capnography is likely to add to patient safety and reduce costs during PSA. Given that cost concerns were central to resistance to including capnography monitoring in guidelines for PSA [21], it may now be time to revisit this discussion.

\section{Conclusions \\ $\nabla$}

Estimates from this modeling analysis suggest that capnography monitoring during endoscopy is likely to be cost-effective versus standard-of-care monitoring. In the base case it was cost saving due to the reduction in AEs. The reduction in AEs with capnography monitoring indicates that outside of cost differentials, capnography monitoring has important applications to patient safety during endoscopy. Given these estimates, it may be time to revisit the question of adding capnography monitoring to standard of care during PSA for endoscopy.

\section{Supplementary material \\ $\checkmark$}

\section{Structured literature search in PubMed}

Literature searches were performed on May 05, 2014 and formed part of a larger research project. With respect to literature informing model development, title and abstract screening of returned articles was performed by RS, with articles presenting original research involving sedation and/or capnography retained for full-text review ( $\bullet$ Table 5 ).

\section{Procedures represented in the model}

Data sources for adverse events, the impact of capnography monitoring, and legal claims cover multiple types of gastrointestinal procedures, endoscopies, and sedation practices:

Table 5 PubMed search strategy.

\begin{tabular}{|c|c|c|c|}
\hline Search & Target & Search terms & Hits \\
\hline$\# 1$ & $\begin{array}{l}\text { All English language, human research } \\
\text { published on or after January 1, } 2008\end{array}$ & $\begin{array}{l}\text { (("2008/01/01"[PDAT] : "2014/05/01"[PDAT]) AND English[lang] NOT Animals } \\
\text { [MeSH:noexp]) }\end{array}$ & $4,212,295$ \\
\hline$\# 2$ & $\begin{array}{l}\text { Literature focused on airway manage- } \\
\text { ment or sedation/analgesia }\end{array}$ & $\begin{array}{l}\text { \#1 AND (Capnography[MAJR] OR Airway Management [MAJR] OR Intubation } \\
\text { [MAIR] OR Oximetry[MESH] OR Sedat*[tiab] OR Analgesi* [tiab] OR "end tidal" } \\
\text { [tiab] OR “end-tidal"[tiab]) }\end{array}$ & 40,354 \\
\hline \#3 & $\begin{array}{l}\text { Literature presenting information on } \\
\text { adverse events }\end{array}$ & $\begin{array}{l}\text { \#2 AND (Apnea[MESH] OR Hypoventilation[MESH] OR hypocapnia[mesh] OR } \\
\text { "Respiratory Distress Syndrome"[MESH] OR Adverse[tiab] OR Hospitalization* } \\
\text { [tiab] OR ((Patient[tiab] OR Airway[tiab]) AND Monitoring[tiab])) }\end{array}$ & 6,928 \\
\hline \#4 & $\begin{array}{l}\text { Those articles focused on monitoring and } \\
\text { patient safety }\end{array}$ & $\begin{array}{l}\text { \#3 AND (Patient Safety[MESH] OR "Carbon Dioxide/blood"[MESH] OR Monitoring } \\
\text { [MESH] OR Risk Assessment[MESH] OR Oxygen/blood[MESH] OR Protocol[tiab] } \\
\text { OR Guideline[tiab] OR Education[tiab]) }\end{array}$ & 929 \\
\hline
\end{tabular}


- Anesthesia [47]

- Colonoscopy [48-50]

- Endoscopic retrograde cholangio-pancreatography $[51,52]$

- Endoscopic ultrasonography $[51,52]$

- Endoscopy $[50,53,54]$

- Esophagogastroduodenoscopy [49]

- Procedural sedation in general [55-58]

- Upper gastrointestinal endoscopy $[50,51]$

\section{Assessing the quality of clinical trials}

Assessment of article quality was done using a modified Jadad scale, whereby additional criteria were included to make the score specific to patient monitoring. The Jadad scale assesses trial design and reporting, with high score of 5 . In addition, we considered the reporting of patient inclusion/exclusion criteria, endpoint criteria, the location of sedation and the staff responsible for patient monitoring. Overall, the maximal score was 8 (high quality) ( $\bullet$ Table6).

\section{Selection of odds ratios}

Lightdale 2006 scored highest for study quality, but is specific to pediatric procedures and so data were derived from Qadeer 2009 and Beitz 2012. As Beitz 2012 enrolled a larger number of patients and was more recent, it was given priority over Qadeer 2009 if both presented data for the same endpoint. As, compared with Beitz 2012, Qadeer 2009 provided lower odds ratios for each endpoint, using data from this study would benefit capnography. (৫ Table 7).

\section{Calculating the odds ratio (OR)}

$\mathrm{OR}=\frac{N^{\text {capnography event }} / N^{\text {capnography non-event }}}{N^{\text {SoC event }} / N^{\text {SOC non-event }}}$

$\mathrm{SE}(\ln [\mathrm{OR}])=\sqrt{\left(\frac{1}{N^{\text {capnography event }}}+\frac{1}{N^{\text {capnography non-event }}}+\frac{1}{N^{\text {SoC event }}}+\frac{1}{N^{\text {SoC non-event }}}\right)}$

$95 \% \mathrm{Cl}=\mathrm{e}^{\ln (\mathrm{OR}) \pm 1.96 \mathrm{SE}(\ln [\mathrm{OR}])}$

As uncertainty around the OR has a log-normal distribution, variation around these parameters is explored in sensitivity analyses using sampling from a log-normal distribution with a mean of the OR and variance described by the standard error (SE) of the natural $\log$ of the OR.

\section{The odds of respiratory compromise}

The OR for respiratory compromise was estimated from a metaanalysis. The analysis by Waugh et al. found that capnography monitoring was 17.6 times more likely to detect respiratory AEs compared with standard of care monitoring.[58] Capnography detected 75 of 94 respiratory events, a probability of detection of 0.798 . Working under the assumptions that only detected events can be prevented and that $10 \%$ of detected events are prevented, the OR for prevention of an event with capnography was calculated to be 0.2152 . The standard error about this OR was assumed to be $50 \%$ of the OR, or 0.1076 .

Probability of detection with capnography, is taken from Waugh et al. [58]:

$\mathrm{p}(\mathrm{cap})=\frac{75}{94}=0.7979$

Table 6 Details of returned clinical trials and analysis of study quality.

\begin{tabular}{|llllll|} 
Study & Country & Modified Jadad & Potential for bias & Hospital setting & $\begin{array}{l}\text { N } \\
\text { (SoC, Cap) }\end{array}$ \\
\hline Beitz 2012 [48] & Germany & 5.5 & High: 3 & Colonoscopy & $757(374,383)$ \\
\hline Lightdale 2006 & US & 8 & Low: 0 & Endoscopy & $163(80,83)$ \\
\hline Qadeer 2009 [52] & US & 7.5 & Moderate: 1 & ERCP and EUS & 247 (124, 123) \\
\hline
\end{tabular}

Table 7 Details of odds ratio $(95 \% \mathrm{Cl})$ for capnography relative to standard of care by study.

\begin{tabular}{|llllll}
\hline Study & Apnea & Desaturation $<90 \%$ & Desaturation $<85 \%$ & Hypotension & Bradycardia \\
\hline Beitz 2012 [48] & & $0.58(0.39 ; 0.86)$ & $0.45(0.23 ; 0.87)$ & $1.04(0.51 ; 2.14)$ & $1.15(0.69 ; 1.9)$ \\
\hline Lightdale 2006 & $0.69(0.35 ; 1.37)$ & & & & \\
\hline Qadeer 2009 [52] & $0.42(0.25 ; 0.7)$ & $0.38(0.23 ; 0.64)$ & $0.4(0.22 ; 0.75)$ & & \\
\hline
\end{tabular}

Table 8 Studies used to calculate the base case patient population.

\begin{tabular}{|c|c|c|c|c|c|}
\hline $\begin{array}{l}\text { Mean cohort } \\
\text { characteristic }\end{array}$ & $\begin{array}{l}\text { Qadeer et al. } \\
\text { control arm, } \\
n=383\end{array}$ & $\begin{array}{l}\text { Qadeer et al. } \\
\text { intervention arm, } \\
n=374\end{array}$ & $\begin{array}{l}\text { Mehta et al. } \\
\text { STOP-BANG } \\
<3, n=125\end{array}$ & $\begin{array}{l}\text { Mehta et al STOP } \\
\text { BANG } \geq 3 \\
n=118\end{array}$ & Model \\
\hline Age, years (SD) & $60.6(14.3)$ & $60.8(14.4)$ & $44.4(16.1)$ & $56.3(14.1)$ & $55.5(14.8)$ \\
\hline Male, \% & 50.4 & 49.2 & 28.8 & 53.4 & $45.3(10.0)^{1}$ \\
\hline $\mathrm{BMI}, \mathrm{kg} / \mathrm{m}^{2}(\mathrm{SD})$ & $26.2(5.6)$ & $26.5(5.8)$ & $24.0(4.7)$ & $28.3(7.2)$ & $26.2(5.9)$ \\
\hline ASA class I, \% & 7.3 & 7.3 & 3.2 & 1.7 & $4.9(10.0)^{1}$ \\
\hline ASA class II, \% & 69.9 & 69.4 & 36.8 & 25.4 & 50.6 \\
\hline ASA class III, \% & 22.8 & 23.4 & 60.0 & 72.9 & 44.5 \\
\hline ASA class IV, \% & 0 & 0 & 0 & 0 & 0 \\
\hline
\end{tabular}

${ }^{1}$ A standard deviation of 10 was assumed for binary characteristics. ASA, American Society of Anesthesiologists; BMI, Body mass index; SD, Standard Deviation. Sources: Mehta et al. 2014 [49] and Qadeer et al. 2009. [52] 
OR for detection with capnography, OR(cap)=17.6, uses the OR presented by from Waugh et al.[58] and uses the random effects model.
OR for detection with SoC, $\mathrm{OR}(\mathrm{SoC})=\mathrm{e}^{-\ln \mathrm{OR}(\mathrm{cap})}=0.0568$, conversion of the OR to standard of care (pulse oximetry only)

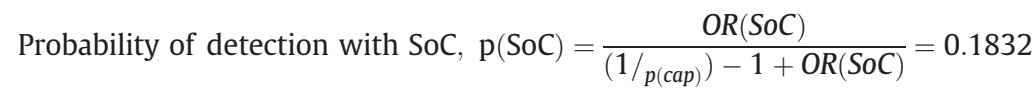

Assume that $10 \%$ of detected events can be prevented:

Events prevented with capnography, $\mathrm{p}\left(\right.$ Prevention $\left._{\text {cap }}\right)=\frac{p(\text { cap })}{100} \times 10=0.08$

Events prevented with SoC, $\mathrm{p}\left(\right.$ Prevention $\left._{\mathrm{SoC}}\right)=\frac{p(\text { SoC })}{100} \times 10=0.02$

Calculation of the OR for pulse oximetry plus capnography relative to standard of care:

OR prevention with capnography, $\mathrm{OR}\left(\right.$ Prevention $\left._{\mathrm{cap}}\right)=\frac{\mathrm{p}\left(\text { Prevention }_{\text {cap }}\right) /\left(1-\mathrm{p}\left(\text { Prevention }_{\text {cap }}\right)\right)}{\mathrm{p}\left(\text { Prevention }_{\mathrm{SoC}}\right) /\left(1-\mathrm{p}\left(\text { Prevention }_{\text {Soc }}\right)\right)}$

OR of an event with capnography, OR $\left(\mathrm{E}_{\mathrm{cap}}\right)=e^{-\ln \mathrm{OR}\left(\text { prevention }_{\text {cap }}\right)}=0.2152$

The OR for an event with capnography did not vary considerably if the assumption regarding the percentage of detected events avoided was adjusted between $2 \%$ and $50 \%$. Using $2 \%$ the OR was 0.2268 , whereas with an assumption of $50 \%$ the OR was 0.1519 .

\section{False positives}

The model accounts for interventions and time associated with false positive events. As these events are false positives, potential interventions were restricted to supplemental oxygen and airway repositioning. In the clinical trial by Qadeer et al., 35 of the 263 patients assessed with capnography erroneously presented with apnea.[52] The probability of pseudo apnea was thus 0.1331 .In the meta-analysis by Waugh et al., 71 false positive and 157 true negative events were reported, giving a false positive probability of 0.3114 with capnography monitoring.[58] This study analyzed multiple definitions of respiratory compromise, the probability $(0.3114)$ is thus assumed to include the probability of pseudo apnea (0.1331) and was adjusted to 0.1783 (0.3114 -0.1331). Given the multiple AEs definitions included in this study, the probability was assigned to airway obstruction.

\section{Patient cohort}

The mean cohort characteristics of the model population are derived from two US based studies $[49,52]$ ( $\bullet$ Table 8).

\section{Combination of odds ratios}

ORs cannot be simply combined, and their combination assumes their independence. In the model, ORs are combined via log transformation. A worked example for calculating the OR for adverse events within the cohort follows:

$O R_{A E}=e^{\sum_{x=1}^{N} \ln O R_{x} \times \frac{C_{X}-R_{x}}{D_{x}}}$

where ORx is the OR associated with risk factor $\mathrm{X}$ ( $\mathrm{rfX}$ ), CX is the cohort value for $\mathrm{rfX}, \mathrm{Rx}$ is the reference value for $\mathrm{rfX}$ from the originating study, and Dx is the denominator for rfX, e.g. 2 if the OR is per increase of 2 in $\mathrm{rXX}$. These factors combine to provide an estimate of $\mathrm{OR}_{\mathrm{AE}}$, the $\mathrm{OR}$ of having an adverse event. To convert this value to an $\mathrm{OR}$ per adverse event, the log transformation of $\mathrm{OR}_{\mathrm{AE}}$ is divided through by the mean number of adverse events per pa- tient. Taking the exponential of the results provides the OR for adverse events per adverse event in this cohort.

\section{Dependency of data}

Data on risk factors linked to the likelihood of adverse events were often taken from independent studies. It is assumed that these data can be combined as independent entities, i.e. that their constituent analyses do not overlap. For example, the risk of adverse events associated with BMI is taken from the study by Wani et al. and the risk of adverse events associated with ASA class is taken from Enestvedt et al:; the assumption is that there is no association between BMI and ASA class $[59,60]$. In the context of the procedure setting, risk is modulated by the monitoring operator and the location of the procedure. Rather than assume independence of these risk factors, the model allows for selection of a primary risk factor (which defaults to the operator) and provision of a weighting factor to describe the proportion of risk from parameter A that is covered by parameter B. The default weight is set to 0.6.

\section{Moderate sedation}

For moderate sedation, the model was informed by publications specific to moderate sedation, where data were available. For all other items, data from the original model was retained. To model moderate sedation the following model parameters were updated in line with the provided reference for moderate sedation:

\section{- Table 9}

\section{One-way sensitivity analyses}

One-way sensitivity analyses were used to assess the impact of changes in unit costs on model outcomes. The majority of cost items have only a small influence on the cost differential between standard of care monitoring and capnography monitoring. Items that reduce the cost saving associated with capnography by $>10 \%$ are increasing the cost of connector lines by a factor of 2.5 and reducing the cost of either positive pressure ventilation or nasal airway by a factor of 2.5 and 4, respectively ( $\bullet$ Fig. S1). The cost differential would be increased by $>10 \%$ through a reduction in the cost of connector lines, and increase in the cost of positive pressure ventilation, nasal airway, premature termination, and damages. 


\begin{tabular}{|lll|}
\hline Parameter & Value & Reference \\
\hline ASA class (I/II/III, IV), \% & $50 / 50 / 0 / 0$ & Assumed due to moderate sedation \\
\hline Patients with an AE, \% & 26.5 & Mean rate over both arms [61] \\
\hline Event rates & & \\
\hline Bradycardia & 0.020 & Mean rate over both arms [61] \\
\hline Desaturation $(<90 \%)$ & 0.252 & Mean rate over both arms [61] \\
\hline Desaturation $(<85 \%)$ & 0.086 & Ratio of $<90$ to $<85$ [62] \\
\hline Hypotension & 0.072 & Mean rate over both arms [61] \\
\hline Respiratory compromise & 0.000063 & {$[63]$} \\
\hline Unplanned admission & 0.00027 & {$[63]$} \\
\hline Odds ratios & & \\
\hline Apnea & $0.72(0.42 ; 1.22)$ & {$[61]$} \\
\hline Desaturation $<90 \%$ & $0.9(0.54 ; 1.51)$ & {$[61]$} \\
\hline Desaturation $<85 \%$ & $0.24(0.09 ; 0.62)$ & {$[61]$} \\
\hline BMI & $1.08(\mathrm{NA})$ & {$[61]$} \\
\hline
\end{tabular}

Table 9 Changes in model parameters to reflect moderate sedation.

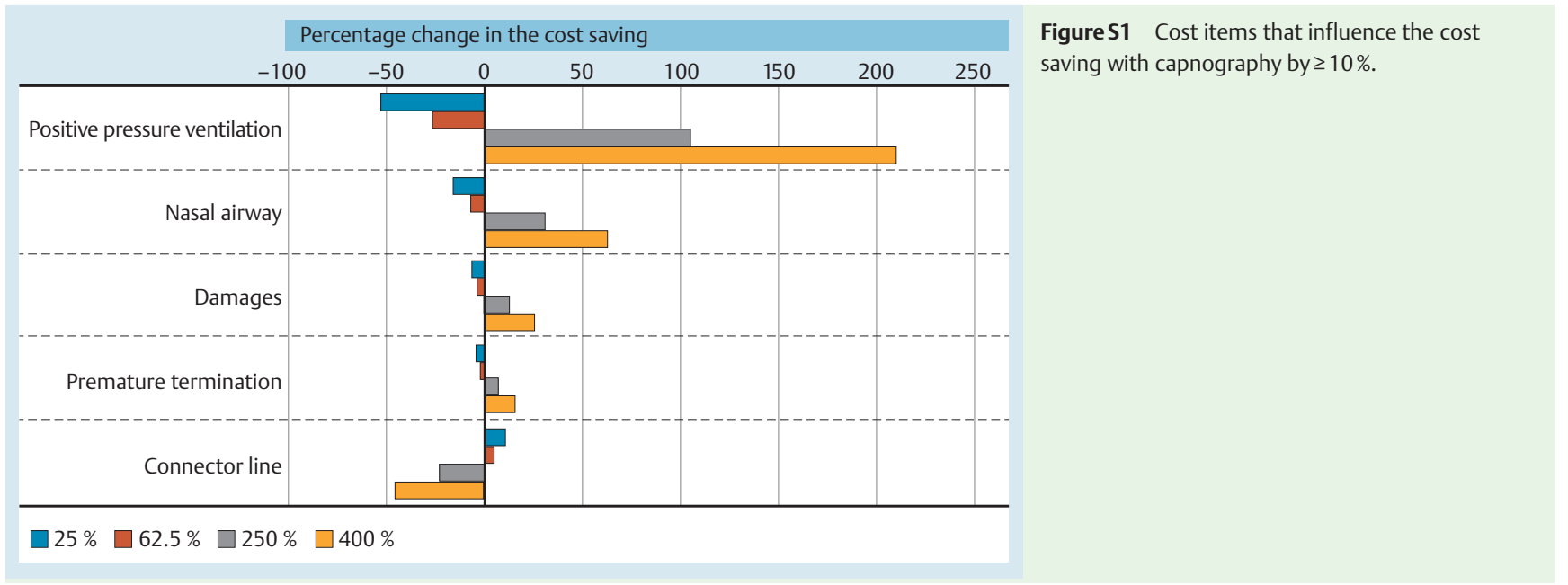

Competing interests: Rhodri Saunders was a full-time employee of Ossian Health Economics and Communications (Basel, Switzerland), which received consultancy fees for work developing the health econnomic model. Rhodri is now director of Coreva Scientific GmbH \& Co. KG. (Freiburg, Germany), which has consultancy contracts with Medtronic Inc. Mary Erslon is a full-time employee of Medtronic Inc. John Vargo is a physician who has consulted for multiple medical devices and pharmaceutical companies. Dr Vargo received no payment for work on this research project or manuscript.

\section{References}

1 Atkinson P, French J, Nice CA. Procedural sedation and analgesia for adults in the emergency department. BMJ 2014; 348: g2965

2 Brown SC, Hart G, Chastain DP et al. Reducing distress for children during invasive procedures: randomized clinical trial of effectiveness of the PediSedate. Paediatr Anaesth 2009; 19: 725 - 731

3 Abraham NS, Fallone CA, Mayrand S et al. Sedation versus no sedation in the performance of diagnostic upper gastrointestinal endoscopy: a Canadian randomized controlled cost-outcome study. Am J Gastroenterol 2004; 99: 1692 - 1699

4 Meredith JR, O'Keefe KP, Galwankar S. Pediatric procedural sedation and analgesia. J Emerg Trauma Shock 2008; 1: 88 -96

5 Porostocky P, Chiba N, Colacino P et al. A survey of sedation practices for colonoscopy in Canada. Can J Gastroenterol 2011; 25: 255-260

6 Liu H, Waxman DA, Main R et al. Utilization of anesthesia services during outpatient endoscopies and colonoscopies and associated spending in 2003-2009. JAMA 2012; 307: 1178-1184

7 Aisenberg J, Cohen LB. Sedation in endoscopic practice. Gastrointest. Endosc. Clin. N. Am 2006; 16: 695-708
8 Godwin SA, Burton JH, Gerardo CJ et al. Clinical policy: procedural sedation and analgesia in the emergency department. Ann Emerg Med 2014; 63: 247-258 e218

9 Srinivasan M, Turmelle M, DePalma LM et al. Procedural Sedation for Diagnostic Imaging in Children by Pediatric Hospitalists using Propofol: Analysis of the Nature, Frequency, and Predictors of Adverse Events and Interventions. J. Pediatr 2012; 160: 801 - 806.e801

10 Cravero JP, Beach ML, Blike GT et al. The incidence and nature of adverse events during pediatric sedation/anesthesia with propofol for procedures outside the operating room: a report from the Pediatric Sedation Research Consortium. Anesth Analg 2009; 108: 795-804

11 Lucendo AJ, Olveira A, Friginal-Ruiz AB et al. Nonanesthesiologist-administered propofol sedation for colonoscopy is safe and effective: a prospective Spanish study over 1000 consecutive exams. Eur J Gastroenterol Hepatol 2012; 24: 787-792

12 Beitz A, Riphaus A, Meining A et al. Capnographic monitoring reduces the incidence of arterial oxygen desaturation and hypoxemia during propofol sedation for colonoscopy: a randomized, controlled study (ColoCap Study). Am J Gastroenterol 2012; 107: 1205-1212

13 Deitch K, Miner J, Chudnofsky CR et al. Does end tidal CO2 monitoring during emergency department procedural sedation and analgesia with propofol decrease the incidence of hypoxic events? A randomized, controlled trial Ann Emerg Med 2010; 55: 258 - 264

14 Qadeer MA, Vargo IJ, Dumot JA et al. Capnographic monitoring of respiratory activity improves safety of sedation for endoscopic cholangiopancreatography and ultrasonography. Gastroenterology 2009; 136: $1568-1576$; quiz 1819-1520

15 Metzner J, Posner KL, Domino KB. The risk and safety of anesthesia at remote locations: the US closed claims analysis. Curr Opin Anaesthesiol 2009; 22: $502-508$ 
16 Robbertze R, Posner KL, Domino KB. Closed claims review of anesthesia for procedures outside the operating room. Curr Opin Anaesthesiol 2006; 19: 436-442

17 Bhananker SM, Posner KL, Cheney FW et al. Injury and liability associated with monitored anesthesia care: a closed claims analysis. Anesthesiology 2006; 104: $228-234$

18 Lightdale JR, Goldmann DA, Feldman HA et al. Microstream capnography improves patient monitoring during moderate sedation: a randomized, controlled trial. Pediatrics 2006; 117: e1170-e1178

19 Adams L, Butas S, Spurlock DJr. Capnography (ETCO2), respiratory depression, and nursing interventions in moderately sedated adults undergoing transesophageal echocardiography (TEE). J Perianesth Nurs 2015; 30: 14-22

20 Langhan ML, Shabanova V, Li FY et al. A randomized controlled trial of capnography during sedation in a pediatric emergency setting. Am J Emerg Med 2015; 33: 25-30

21 American Society for Gastrointestinal Endoscopy. American College of Gastroenterology. Association TAG. Universal adoption of capnography for moderate sedation in adults undergoing upper endoscopy and colonoscopy has not been shown to improve patient safety or clinical outcomes and significantly increases costs for moderate sedation. 2012

22 Weaver J. The latest ASA mandate: $\mathrm{CO}(2)$ monitoring for moderate and deep sedation. Anesth Prog 2011; 58: $111-112$

23 Friedrich-Rust $M$, Welte $M$, Welte $C$ et al. Capnographic monitoring of propofol-based sedation during colonoscopy. Endoscopy 2014; 46: $236-244$

24 Walsh BK, Crotwell DN, Restrepo RD. Capnography/Capnometry during mechanical ventilation: 2011. Respir Care 2011; 56: 503 - 509

25 Caro JJ, Briggs AH, Siebert $U$ et al. Modeling good research practicesoverview: a report of the ISPOR-SMDM Modeling Good Research Practices Task Force-1. Value Health 2012; 15: 796-803

26 Scheuermeyer FX, Andolfatto G, Qian $H$ et al. Does the sedation regimen affect adverse events during procedural sedation and analgesia in injection drug users? CJEM 2013; 15: 279-288

27 Mehta PP, Kochhar G, Kalra S et al. Can a validated sleep apnea scoring system predict cardiopulmonary events using propofol sedation for routine EGD or colonoscopy? A prospective cohort study Gastrointest Endosc 2014; 79: 436-444

28 Wani S, Azar R, Hovis CE et al. Obesity as a risk factor for sedation-related complications during propofol-mediated sedation for advanced endoscopic procedures. Gastrointest Endosc 2011; 74: 1238-1247

29 Enestvedt BK, Eisen GM, Holub J et al. Is the American Society of Anesthesiologists classification useful in risk stratification for endoscopic procedures? Gastrointest Endosc 2013; 77: 464-471

30 Waugh JB, Epps CA, Khodneva YA. Capnography enhances surveillance of respiratory events during procedural sedation: a meta-analysis. J Clin Anesth 2011; 23: 189-196

31 Statistics USBoL. Consumer price index - all urban consumers. In. series ID: CUUR0000SA0 ed. Postal Square Building, 2 Massachusetts Avenue, NE Washington, DC 20212-0001. U.S. Bureau of Labor Statistics; 2015

32 Couloures KG, Beach M, Cravero JP et al. Impact of provider specialty on pediatric procedural sedation complication rates. Pediatrics 2011; 127: e1154-e1160

33 Ferguson K, Young J, Panagopoulos $P$ et al. Anesthesia Related Closed Claims and Litigations at the Detroit Medical Center: Analysis, Lessons Learned, and Conclusions. Open J Anesthesiol 2014; 4: 88-98

34 Maglinte DD, Applegate KE, Rajesh A et al. Conscious sedation for patients undergoing enteroclysis: comparing the safety and patient-reported effectiveness of two protocols. Eur J Radiol 2009; 70: 512-516

35 Mehta P, Kochhar G, Albeldawi M et al. Capnographic Monitoring Does Not Improve Detection of Hypoxemia in Colonoscopy With Moderate Sedation: A Randomized, Controlled Trial. Am J Gastroenterol 2014; 109: S588

36 Sharma VK, Nguyen CC, Crowell MD et al. A national study of cardiopulmonary unplanned events after GI endoscopy. Gastrointest Endosc 2007; 66: $27-34$

37 Finn JP. Sedation in MR Imaging: What Price Safety? Radiology 2000; 216: $633-634$

38 Garcia RT, Cello JP, Nguyen MH et al. Unsedated ultrathin EGD is well accepted when compared with conventional sedated EGD: a multicenter randomized trial. Gastroenterology 2003; 125: 1606-1612
39 Dunham CM, Hileman BM, Hutchinson AE et al. Perioperative hypoxemia is common with horizontal positioning during general anesthesia and is associated with major adverse outcomes: a retrospective study of consecutive patients. BMC Anesthesiol 2014; 14: 43

40 Green SM, Krauss B. Pulmonary aspiration risk during emergency department procedural sedation-an examination of the role of fasting and sedation depth. Acad Emerg Med 2002; 9: 35-42

41 Wehrmann T, Riphaus A. Sedation with propofol for interventional endoscopic procedures: a risk factor analysis. Scand. J. Gastroenterol 2008; 43: $368-374$

42 Rex DK, Heuss LT, Walker JA et al. Trained registered nurses/endoscopy teams can administer propofol safely for endoscopy. Gastroenterology 2005; 129: $1384-1391$

43 Jensen JT, Vilmann P, Horsted T et al. Nurse-administered propofol sedation for endoscopy: a risk analysis during an implementation phase. Endoscopy 2011; 43: 716- 722

44 Vargo JJ. Procedural sedation. Curr Opin Gastroenterol 2010; $26: 421$ 424

45 Bhatt M, Kennedy RM, Osmond MH et al. Consensus-based recommendations for standardizing terminology and reporting adverse events for emergency department procedural sedation and analgesia in children. Ann Emerg Med 2009; 53: 426 - 435 e424

46 Melendez E, Bachur R. Serious adverse events during procedural sedation with ketamine. Pediatr Emerg Care 2009; 25: 325-328

\section{Supplementary References}

47 Ferguson K, Young J, Panagopoulos $P$ et al. Anesthesia Related Closed Claims and Litigations at the Detroit Medical Center: Analysis, Lessons Learned, and Conclusions. Open J Anesthesiol 2014; 4: 88-98

48 Beitz A, Riphaus A, Meining A et al. Capnographic monitoring reduces the incidence of arterial oxygen desaturation and hypoxemia during propofol sedation for colonoscopy: a randomized, controlled study (ColoCap Study). Am J Gastroenterol 2012; 107: 1205-1212

49 Mehta PP, Kochhar G, Kalra S et al. Can a validated sleep apnea scoring system predict cardiopulmonary events using propofol sedation for routine EGD or colonoscopy? A prospective cohort study Gastrointest Endosc 2014; 79: 436-444

50 Vargo JJ. Procedural sedation. Curr Opin Gastroenterol 2010; 26: 421 424

51 Wehrmann T, Riphaus A. Sedation with propofol for interventional endoscopic procedures: a risk factor analysis. Scand. J. Gastroenterol 2008; 43: 368-374

52 Qadeer MA, Vargo JJ, Dumot JA et al. Capnographic monitoring of respiratory activity improves safety of sedation for endoscopic cholangiopancreatography and ultrasonography. Gastroenterology 2009; 136: 1568 - 1576 ; quiz 1819-1520

53 Rex DK, Heuss LT, Walker JA et al. Trained registered nurses/endoscopy teams can administer propofol safely for endoscopy. Gastroenterology 2005; 129: $1384-1391$

54 Jensen JT, Vilmann P, Horsted T et al. Nurse-administered propofol sedation for endoscopy: a risk analysis during an implementation phase. Endoscopy 2011; 43: 716-722

55 Green SM, Krauss B. Pulmonary aspiration risk during emergency department procedural sedation-an examination of the role of fasting and sedation depth. Acad Emerg Med 2002; 9: 35-42

56 Srinivasan M, Turmelle M, DePalma LM et al. Procedural Sedation for Diagnostic Imaging in Children by Pediatric Hospitalists using Propofol: Analysis of the Nature, Frequency, and Predictors of Adverse Events and Interventions. J Pediatr 2012; 160: 801 -806.e801

57 Couloures KG, Beach M, Cravero JP et al. Impact of provider specialty on pediatric procedural sedation complication rates. Pediatrics 2011; 127: e1154-e1160

58 Waugh JB, Epps CA, Khodneva YA. Capnography enhances surveillance of respiratory events during procedural sedation: a meta-analysis. J Clin Anesth 2011; 23: 189-196

59 Wani S, Azar R, Hovis CE et al. Obesity as a risk factor for sedation-related complications during propofol-mediated sedation for advanced endoscopic procedures. Gastrointest Endosc 2011; 74: 1238-1247

60 Enestvedt BK, Eisen GM, Holub J et al. Is the American Society of Anesthesiologists classification useful in risk stratification for endoscopic procedures? Gastrointest Endosc 2013; 77: 464-471 
61 Maglinte DD, Applegate KE, Rajesh A et al. Conscious sedation for patients undergoing enteroclysis: comparing the safety and patient-reported effectiveness of two protocols. Eur J Radiol 2009; 70: 512 - 516

62 Mehta P, Kochhar G, Albeldawi M et al. Capnographic Monitoring Does Not Improve Detection Of Hypoxemia In Colonoscopy With Moderate Sedation. A Randomized, Controlled Trial American College of Gastro-

enterology 2014 Annual Scientific Meeting Philadelphia, PA, USA: 2014

63 Sharma VK, Nguyen CC, Crowell MD et al. A national study of cardiopulmonary unplanned events after GI endoscopy. Gastrointest Endosc 2007; 66: $27-34$ 